\title{
Numerical Study on Seismic Performances of Geogrid Reinforced Soil Retaining Walls in Liquefiable Backfill Sand
}

\author{
Li-yan Wang ${ }^{1, *}$, Peng Gao ${ }^{1}$ and Susumu Iai ${ }^{2}$ \\ ${ }^{1}$ School of Civil and architectural engineering, Jiangsu University of Science and Technology, 212003, Zhenjiang, China \\ ${ }^{2}$ Disaster Prevention Research Institute, Kyoto University, Gokasho, Uji, Kyoto, 611-0011, Japan
}

Received 15 June 2013; Accepted 23 January 2014

\begin{abstract}
Geogrid reinforced soil retaining walls are relative flexible retaining soil structures. The seismic mechanism of geogrid reinforced soil retaining walls with liquefiable backfill soils has not been clear during earthquakes. A strain multiple mechanism model can describe the generation and development of pore water pressures in saturated sand under cyclic loadings and undrained conditions. It can also describe the rotation of principal stress axes to simulate cyclic behaviors of anisotropic consolidated sand. The multiple mechanism model is applied to investigate seismic performances of geogrid reinforced soil retaining walls with liquefied backfill sand. In order to study the reinforced effect of geogrid for seismic stability of retaining walls, three retaining wall models are constructed, which are respectively an unreinforced soil retaining wall with saturated backfill sand, a geogrid reinforced soil retaining wall with saturated backfill sand and a geogrid reinforced soil retaining wall with dry backfill sand. Seismic horizontal deformations, seismic settlements, excess pore water pressures and strains of geogrids are compared in detail. The comparison results indicate that geogrids can still effectively decrease seismic performances of geogrid reinforced soil retaining walls with liquefied backfill sand. Drainage measures in geogrid reinforced soil retaining walls must be taken well in the construction. Some important seismic design points are achieved.
\end{abstract}

Keywords: geogrid reinforced soil retaining wall; reinforced internal force; earthquake; finite difference method; shaking table test

\section{Introduction}

Geogrid reinforced soil retaining walls have been used widely in many fields because of its many merits. At present, lakeshore walls of the sluice, bank slopes, docks, bridge abutments and dams are made into reinforced soil retaining walls as well. However, the geo-grid reinforced soil retaining wall is a relative flexible retaining structure compared with gravity retaining walls, and protruding swelling deformations and overturning multiple damages occurred respectively [1].

The seismic behaviors of geogrid reinforced soil retaining walls have become academic research mainstream. Broad discussions about seismic designs and seismic behaviors of the reinforced retaining walls were taken by global geotechnical engineering research communities. J. Izawa [2] tested the effect of the stability of the geo-grid reinforced retaining wall under saturated condition of backfill sand by conducting centrifuge shaking table test. K.Z.Z. Lee [3] presented the results of numerical simulation of three full-scale geosynthetic-reinforced soil walls that were seismically loaded by a shaking table. The calculated results indicated seismic wall displacement decreases with decreasing reinforcement spacing. Factors responsible for comparison discrepancy are discussed. Variability within

\footnotetext{
*E-mail address: wly_yzu@163.com
}

ISSN: 1791-2377 @ 2014 Kavala Institute of Technology. All rights reserved. the measured data is thought to have contributed to some of the comparison discrepancy. S.Rajesh [4] examined the hydro- mechanical behavior of soil barriers with and without the inclusion of geogrid reinforcement within the soil barrier of landfill cover systems. The effect of geogrid type on the deformation behavior of the soil barrier subjected to various ranges of distortion levels was examined through centrifuge tests carried out at $40 \mathrm{~g}$. The results from the present study suggest that the hydromechanical behavior of the soil barriers can be improved with a suitable geogrid layer having adequate tensile load strain characteristics. Maotian [5] developed finite element analysis method towards geo-grid reinforced soil retaining wall, and computed the stress and deformation of a certain full-scale testing wall by the FEM. Liu Huabei [6] used a finite element program to study the strengthening of load and deformation modes under seismic loads, and discovered that the deformation mode of wall is a significant double wedge. Qiang Ma [7] introduced the mechanism of the geogrid-reinforced soil for alleviating settlement at bridge approaches. According to the requirements of driving comfort, the length of geogrid reinforcement behind the abutment can be preliminarily calculated. The stresses acting on geogrid reinforcements were theoretically analyzed, and the analytical expression to calculate the tensile forces of geogrid was obtained. Gui Yang [8] carried out cyclic triaxial tests to investigate dynamic deformation characteristics of reinforced and unreinforced rockfill material. The influences of confining pressure, numbers of 
reinforcement layer and reinforcement location were analyzed. It was shown that the dynamic shear modulus and damping ratio of reinforced rockfill material are smaller than those of unreinforced rockfill material under lower confining pressure.It can be seen that the Rayleigh wave affects the value of seismic active earth pressure considerably.

\section{Calculation Method}

FLIP is a finite element analysis program for liquefaction process and has been widely applied to study seismic response of geo-structures in sandy soils. The core of the program is based on multi-shear mechanism model which was develop by Iai et al. [9], and the prediction of excess pore water pressure in soil is its outstanding characteristics.

In recent years, there have been many applications of the numerical method. Ozutsumi [10] applied the effective stress analysis method to study liquefaction-induced deformation in river dikes. Tobita[11] used the numerical method to study recently discovered nonlinear behavior of the surface ground motion. Hussien [12] applied FLIP to study the soil-pile separation effect on the performance of pile group under static and dynamic lateral loads.

At present, the seismic mechanism of geogrid reinforced soil retaining walls has not been clear during earthquakes in liquefiable backfill. In this paper, FLIP is applied to investigate seismic performances of geogrid reinforced soil retaining walls with liquefiable backfill sand, especially study the reinforced effects of geogrid in the situation. Motion equations and constitutive model of soils were introduced in above references.

\section{Calculation Model}

\subsection{Analysis Model}

In order to investigate the reinforced effect of geogrid in reinforced soil retaining wall with liquefiable backfill sand, three retaining wall models are constructed. Model 1 is an unreinforced soil retaining wall with saturated backfill sand. Model 2 is a geogrid reinforced soil retaining wall with saturated backfill sand. Model 3 is a geogrid reinforced soil retaining wall with dry backfill sand. Fig. 1 shows the analysis model of Model 2. Fig. 2 and Fig. 3 are respectively the schematic of geogrid research parts and the schematic of research nodes and elements.

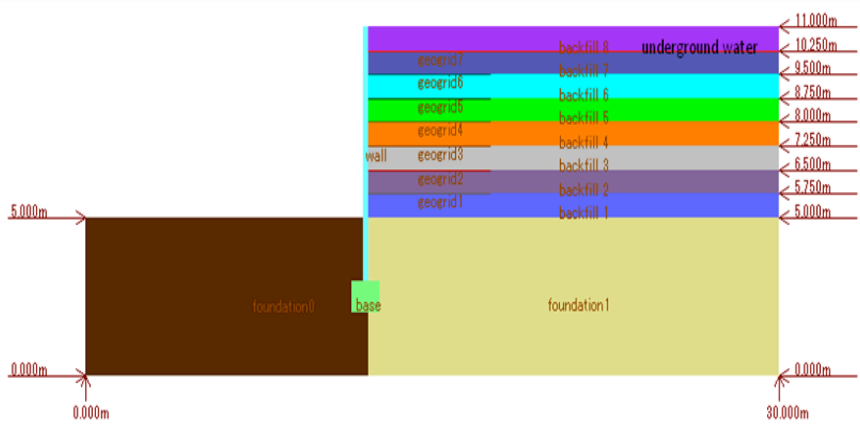

Fig. 1. Model 2: geogrid reinforced soil retaining wall with saturated backfill sand
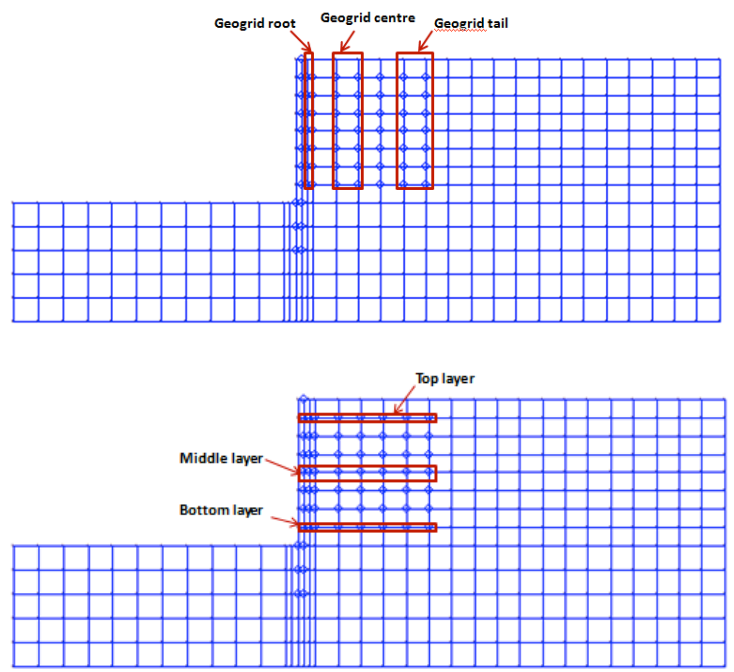

Fig. 2. Schematic of geogrid research parts

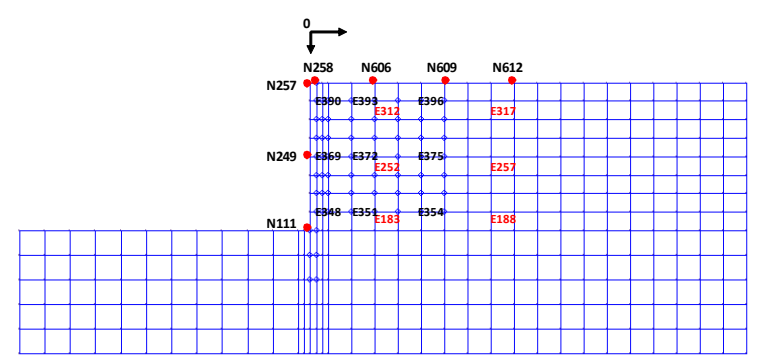

Fig.3. Schematic of research nodes and elements

The analysis process in the study includes the following four contents:

1) Gravity analysis of free field

2) Earthquake response analysis of free field

3) Gravity analysis of main analysis domain

4) Earthquake response analysis of main analysis domain

\subsection{Material properties}

Multi-shear spring elements are applied to simulate soils and the material parameters of soils are given in Table 1 . Initial mean effective confining pressure is $3 / 4$ of vertical pressure, the initial shear modulus and bulk modulus is calculated as the following formulas (1) and (2), the shear modulus and the bulk modulus are calculated as the formulas (3) and (4) in the FLIP, parameters for dilatancy are confirmed by equivalent counts of standard penetration test. Linear planar elements are applied to simulate the reinforced wall and the base, and the material parameters are listed in Table 2. Nonlinear beam elements are used to simulate geogrids; geogrids are made of high density polyethylene, static ultimate strength is $120 \mathrm{kN} / \mathrm{m}$; the material parameters of nonlinear beam elements are confirmed by the tensile force of this geogrid at the strain of $2 \%$, which are listed in Table 3 . Joint elements are defined between wall and soils and between geogrids and soils, and the material parameters are given in Table 4 . 


$$
\begin{gathered}
G_{\max }=\rho V_{s}^{2} \\
K_{\max }=G_{\max } \frac{2(1+v)}{3(1-2 v)} \\
G=G_{\max }\left(\frac{c \cdot \operatorname{ctg} \phi_{f}^{\prime}-\sigma_{m}^{\prime}}{c \cdot \operatorname{ctg} \phi_{f}^{\prime}-\sigma_{m 0}^{\prime}}\right)^{m_{G}} \\
K=K_{\max }\left(\frac{c \cdot \operatorname{ctg} \phi_{f}^{\prime}-\sigma_{m}^{\prime}}{c \cdot c \operatorname{ctg} \phi_{f}^{\prime}-\sigma_{m 0}^{\prime}}\right)^{m_{K}}
\end{gathered}
$$

Table 2 Material parameters of the wall and the base

\begin{tabular}{c|c|c|c|c}
\hline \multirow{2}{*}{ name } & $\begin{array}{c}\text { normal } \\
\text { stiffness }\end{array}$ & $\begin{array}{c}\text { shear } \\
\text { stiffness }\end{array}$ & $\begin{array}{c}\text { Cohe- } \\
\text { sion }\end{array}$ & $\begin{array}{c}\text { friction } \\
\text { angle }\end{array}$ \\
\cline { 2 - 5 } & $K_{n}$ & $K_{s}$ & $c$ & $\phi$ \\
\cline { 2 - 5 } $\mathrm{kN} / \mathrm{m}^{2}$ & $\mathrm{kN} / \mathrm{m}^{2}$ & $\mathrm{kPa}$ & $\circ$ \\
\hline wall and clay & $1.0 \mathrm{E}+7$ & $1.0 \mathrm{E}+6$ & 15 & 15 \\
\hline wall and sand & $1.0 \mathrm{E}+7$ & $1.0 \mathrm{E}+6$ & 0 & 31 \\
\hline $\begin{array}{c}\text { geogrid and } \\
\text { sand }\end{array}$ & $1.0 \mathrm{E}+7$ & $1.0 \mathrm{E}+6$ & 20 & 31 \\
\hline
\end{tabular}

Table 4 Material parameters of joint elements

\begin{tabular}{c|c|c|c}
\hline \multirow{2}{*}{ name } & $\begin{array}{c}\text { Mass } \\
\text { density }\end{array}$ & $\begin{array}{c}\text { elastic } \\
\text { modulus }\end{array}$ & $\begin{array}{c}\text { poison } \\
\text { ratio }\end{array}$ \\
\cline { 2 - 4 } & $\rho_{\left(\mathrm{t} / \mathrm{m}^{3}\right)}$ & $\mathrm{E}\left(\mathrm{kN} / \mathrm{m}^{2}\right)$ & $v$ \\
\hline wall & 2.4 & $3.0 \mathrm{E}+7$ & 0.17 \\
\hline base & 2.5 & $3.25 \mathrm{E}+7$ & 0.17 \\
\hline
\end{tabular}

\subsection{Boundary conditions}

Lateral ground element is applied to simulate lateral viscous boundary in earthquake response analysis of main analysis domain. Bottom ground element is applied to simulate bottom viscous boundary in earthquake response analysis of free field and earthquake response analysis of main analysis domain. The material parameters of lateral viscous boundary and bottom viscous boundary include mass density, P-wave velocity and S-wave velocity which are listed in Table 1. The same freedom degrees are defined in $\mathrm{x}$-direction and $\mathrm{y}$-direction in earthquake response analysis of free field.

\subsection{Input motion}

The input earthquake motion recording is given in Fig.4, which is Kobe wave in 1995. According to seismic design intensities in the most regions of our nation, the seismic intensity is confirmed as $0.2 \mathrm{~g}$ in the following studies.

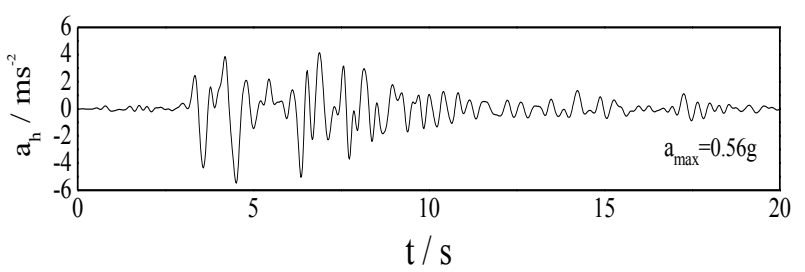

Fig. 4. Input earthquake motion recording

\section{Calculation results}

\subsection{Seismic horizontal deformations}

Fig. 5 shows the whole outlines of seismic residual deformations of three retaining walls. It can be seen that the deformation of model 1 is largest, and the deformation of model 3 is smallest. Fig. 6 is time histories of seismic horizontal deformations of retaining wall tops (N257) and Fig. 7 is distributions of seismic residual deformations of retaining walls along the wall depth. The horizontal deformations decrease with the increase of wall depth and deformations at retaining wall tops are largest. Compared model 1 with model 2 , the horizontal deformation of model 2 on the wall top decreases by $34 \%$, it indicates thatgeogrids could effectively decrease seismic lateral displacements of walls and presented a lateral deformation resistance ability. Compared model 3 with model 2, deformations of model 3 is lower, the horizontal deformation of model 3 on the wall top decreases by $43 \%$. Hence, drainage measures of geogrid reinforced soil retaining walls must be taken in the construction.

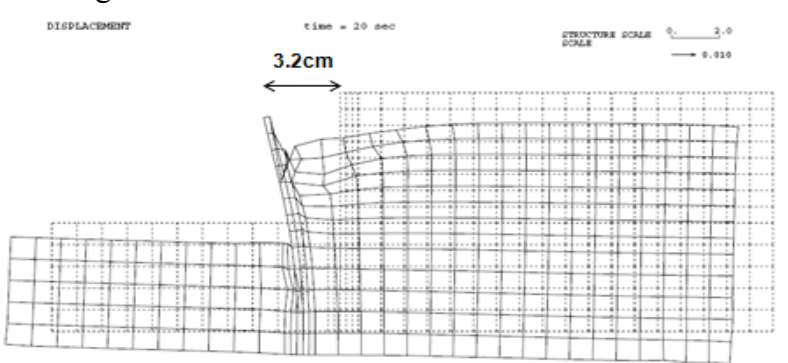

(a) model 1

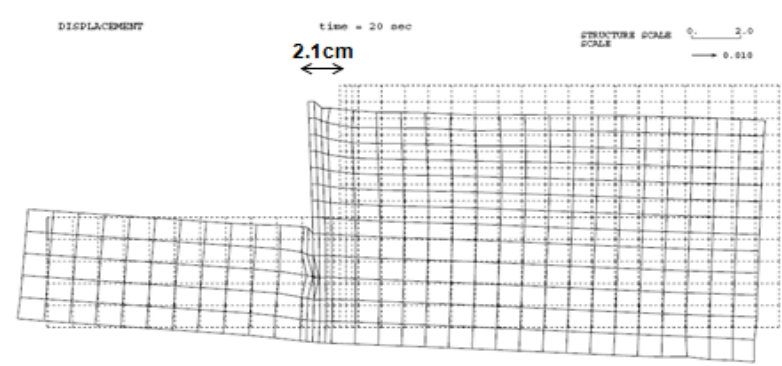

(b) model 2

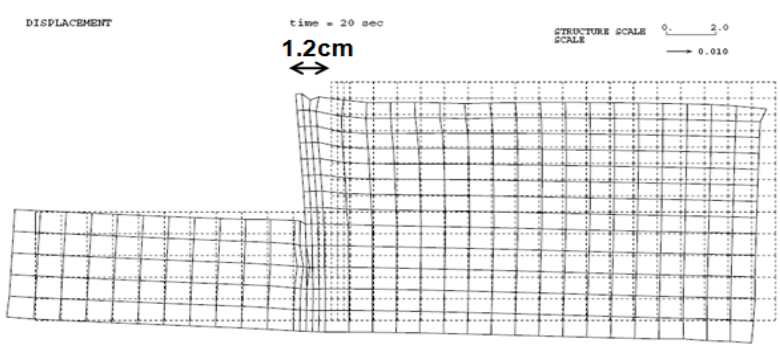

(c) model 3

Fig. 5. Seismic residual deformations of retaining walls 
Li-yan Wang Peng Gao and Susumu Iai /Journal of Engineering Science and Technology Review 7 (1) (2014) 109- 115

Table 1 Material parameters of soil (multi-spring element)

\begin{tabular}{|c|c|c|c|c|c|c|c|c|c|c|c|c|c|c|c|c|c|c|}
\hline \multirow{4}{*}{ Layer } & \multicolumn{2}{|c|}{ mass density } & \multirow{2}{*}{$\begin{array}{l}\text { S-wave } \\
\text { velocity }\end{array}$} & \multirow{2}{*}{$\begin{array}{l}\text { P-wave } \\
\text { velocity }\end{array}$} & \multirow{2}{*}{$\begin{array}{l}\text { mean } \\
\text { effective } \\
\text { confining } \\
\text { ressure }\end{array}$} & \multirow{2}{*}{$\begin{array}{c}\text { initial } \\
\text { shear } \\
\text { stiffness }\end{array}$} & \multirow{2}{*}{$\begin{array}{l}\text { initial } \\
\text { bulk } \\
\text { modulus }\end{array}$} & \multirow{2}{*}{$\begin{array}{c}\text { poison } \\
\text { ratio }\end{array}$} & \multirow{2}{*}{ porosity } & \multirow{2}{*}{$\begin{array}{l}\text { max. of } \\
\text { attenuation } \\
\text { factor }\end{array}$} & \multirow{2}{*}{ Cohesion } & \multirow{2}{*}{$\begin{array}{l}\text { Internal } \\
\text { friction } \\
\text { angle }\end{array}$} & \multirow{2}{*}{$\begin{array}{c}\text { Phase } \\
\text { transformation } \\
\text { angle }\end{array}$} & \multirow{2}{*}{\multicolumn{5}{|c|}{ liquefaction parameters }} \\
\hline & $\begin{array}{l}\text { Static } \\
\text { analysis }\end{array}$ & $\begin{array}{c}\text { Dynamic } \\
\text { analysis }\end{array}$ & & & & & & & & & & & & & & & & \\
\hline & $\rho$ & $\rho$ & $V_{s}$ & $V_{\mathrm{p}}$ & $\sigma_{m 0}{ }^{\prime}$ & $G_{\max }$ & $K_{\max }$ & $v$ & $n$ & $H_{\text {max }}$ & $c$ & $\phi_{f}^{\prime}$, & $\phi_{p}^{\prime}$ & & & & & \\
\hline & $t / \mathrm{m}^{3}$ & $t / \mathrm{m}^{3}$ & $\mathrm{~m} / \mathrm{s}$ & $\mathrm{m} / \mathrm{s}$ & $\mathrm{kPa}$ & $\mathrm{MPa}$ & $\mathrm{MPa}$ & 0.33 & - & - & $\mathrm{kPa}$ & $\circ$ & $\circ$ & $s_{1}$ & $w_{1}$ & $p_{1}$ & $p_{2}$ & $c_{1}$ \\
\hline f 0 & 0.8 & 1.8 & 160 & 317 & 32 & 46.08 & 119.80 & 0.33 & 0.55 & 0.20 & 40 & 10.0 & - & - & - & - & - & - \\
\hline $\mathrm{fl}$ & 0.8 & 1.8 & 290 & 580 & 111 & 59.79 & $155 . .45$ & 0.33 & 0.55 & 0.20 & 60 & 5.0 & - & - & - & - & - & - \\
\hline bf 1 & 1.0 & 1.9 & 200 & 395 & 98 & 80.00 & 208.00 & 0.33 & 0.45 & 0.24 & 0 & 35.0 & 28.0 & 0.005 & 5.50 & 0.50 & 1.02 & 1.60 \\
\hline bf 2 & 1.0 & 1.9 & 190 & 378 & 98 & 72.20 & 187.72 & 0.33 & 0.45 & 0.24 & 0 & 35.0 & 28.0 & 0.005 & 5.50 & 0.50 & 1.02 & 1.60 \\
\hline bf 3 & 1.0 & 1.9 & 180 & 358 & 98 & 64.80 & 168.48 & 0.33 & 0.45 & 0.24 & 0 & 35.0 & 28.0 & 0.005 & 5.50 & 0.50 & 1.02 & 1.60 \\
\hline bf 4 & 1.0 & 1.9 & 170 & 340 & 98 & 57.800 & 150.280 & 0.33 & 0.45 & 0.24 & 0 & 35.0 & 28.0 & 0.005 & 5.50 & 0.50 & 1.02 & 1.60 \\
\hline bf 5 & 1.0 & 1.9 & 160 & 317 & 98 & 51.200 & 133.120 & 0.33 & 0.45 & 0.24 & 0 & 35.0 & 28.0 & 0.005 & 5.50 & 0.50 & 1.02 & 1.60 \\
\hline bf 6 & 1.0 & 1.9 & 150 & 298 & 98 & 45.00 & 117.00 & 0.33 & 0.45 & 0.24 & 0 & 35.0 & 28.0 & 0.005 & 5.50 & 0.50 & 1.02 & 1.60 \\
\hline bf 7 & 1.0 & 1.9 & 140 & 280 & 98 & 39.20 & 192.10 & 0.33 & 0.45 & 0.24 & 0 & 35.0 & 28.0 & 0.005 & 5.50 & 0.50 & 1.02 & 1.60 \\
\hline bf 8 & 1.0 & 1.9 & 120 & 238 & 98 & 28.80 & 117.00 & 0.33 & 0.45 & 0.24 & 0 & 35.0 & - & - & - & - & - & - \\
\hline
\end{tabular}

Table 3 Material parameters of geogrid ( beam element)

\begin{tabular}{c|c|c|c|c|c|c|c}
\hline \multirow{2}{*}{ name } & Mass density & Poison ratio & Inertial moment & Elastic modulus & Shear modulus & Cross-section area & bending stiffness \\
\cline { 2 - 7 } & $\rho_{\left(\mathrm{t} / \mathrm{m}^{3}\right)}$ & $v$ & $I\left(\mathrm{~m}^{4}\right)$ & $\begin{array}{c}\mathrm{E} \\
\left(\mathrm{kN} / \mathrm{m}^{2}\right)\end{array}$ & $G_{s}\left(\mathrm{kN} / \mathrm{m}^{2}\right)$ & $\mathrm{A}\left(\mathrm{m}^{2}\right)$ & $E I\left(\mathrm{kN} \cdot \mathrm{m}^{2}\right)$ \\
\hline $\mathrm{g} 1 \sim \mathrm{g} 8$ & 1.0 & 0.22 & $1.67 \mathrm{E}-4$ & $1.0 \mathrm{E}+5$ & $4.10 \mathrm{E}+4$ & 0.002 \\
\hline
\end{tabular}




\subsection{Excess pore water pressures}

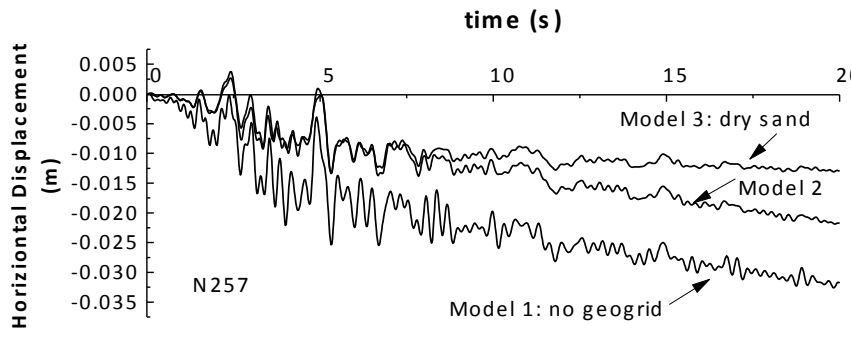

Fig. 6. Time histories of seismic deformations of retaining wall tops

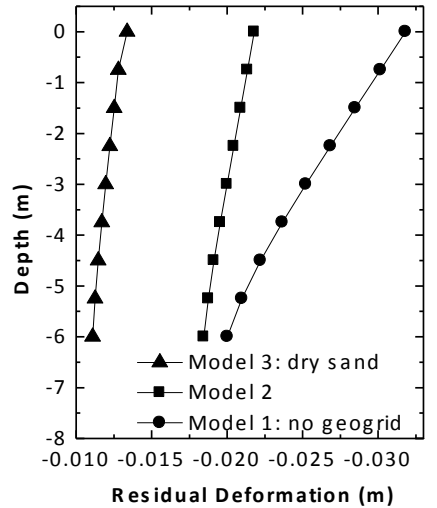

Fig.7. Distributions of seismic residual deformations of retaining walls along the wall depth

\subsection{Settlements of backfill surface}

Fig. 8 presents time histories of seismic settlements of reinforced zone surface. Fig. 9 is distributions of seismic residual settlements of backfill surfaces. Due to the outwards movements of retaining walls, settlements of backfill surfaces in reinforced zone are relative larger than unreinforced zone. Because geogrid roots are fixed into the wall face, the settlements of backfill sand which is close to wall face are relative smaller than other positions. Compared model 1 with model 2 , the seismic settlement of N606 in model 2 decreases by $29 \%$. Compared model 3 with model 2 , settlements of the whole backfill surface of model 3 are smaller, the settlement of N606 in the reinforced zone of model 3 decreases by $14 \%$. It shows that the geogrid could effectively decrease seismic settlements of the backfill surfaces, but it is still important to construct good drainage measures.

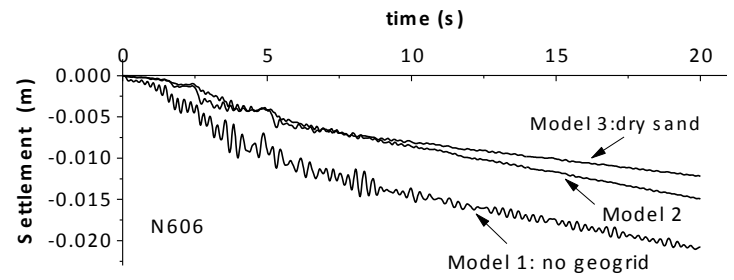

Fig.8. Time histories of seismic settlements of reinforced zone surface

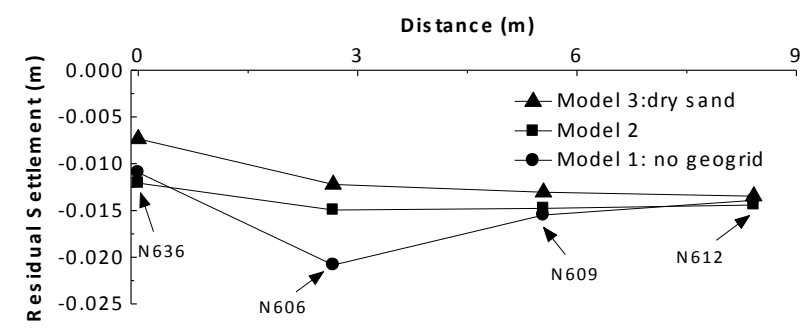

Fig. 9. Distributions of seismic residual settlements of backfill surfaces
Fig. 10 is time histories of excess pore water pressures in othe unreinforced zone and the reinforced zone of model 2. Fig. 11 is distributions of maximum excess pore water pressure ratios of model 2. It can be seen that excess pore pressure ratios decrease with the increase of the wall depth. The development levels of excess pore water pressures in reinforced zone are smaller than unreinforced zone. In the same soil height, compared E312 with E317, the excess pore pressure ratio of E312 decreases by $17 \%$; compared E252 with E257, the excess pore pressure ratio of E252 decreases by $31 \%$; compared E183 with E188, the excess pore pressure ratio of E183 decreases by $21 \%$. It indicates that geogrids in reinforced zone could effectively decrease the development of excess pore pressures; especially for the middle-layer geogrid reinforced soil, the effect of decreasing the excess pore pressure is distinct. Therefore, Geogrids provide a liquefaction mitigation function for the reinforced soil retaining wall with saturated sand.

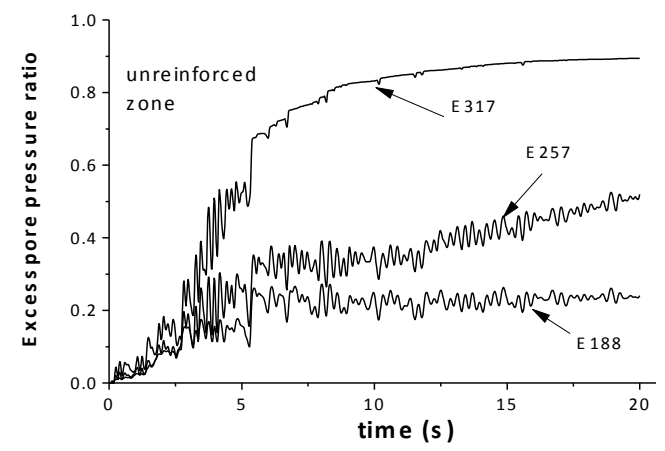

(a) unreinforced zone

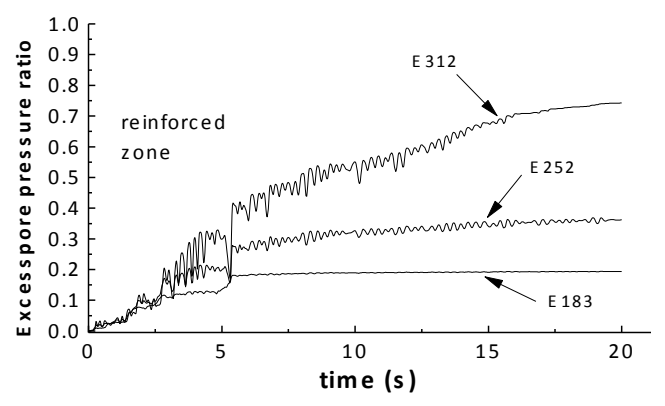

(b) reinforced zone

Fig. 10. Time histories of excess pore pressures of model 2

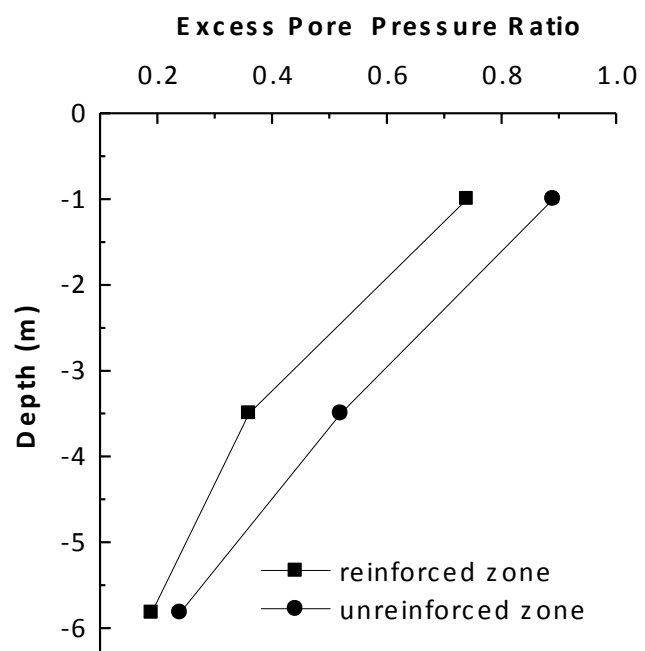

Fig. 11. Distributions of maximum excess pore water pressures of model 2 


\section{4 geogrid strain}

Fig.12 is time histories of geogrid strains of model 2. Fig. 13 presents distributions of geogrid strains along geogrid lengths. Geogrid strains increase with the increase of time; after the time is $10 \mathrm{~s}$, the geogrid strains become a stable state. For the bottom-layer geogrid, the strain of E348 is largest, and the strain of E354 is negative, which show the geogrid root has a larger force and the geogrid tail is in a compressed state. For the middle-layer geogrid, the strain of E372 is largest, and the strain of E369 is smallest, which show the geogrid centre has a larger force and the geogrid tail has a smaller force. For the top-layer geogrid, every element is in a tension state.; the strain of E393 is largest, and the strain of E369 is close to the strain of E390, which show the geogrid centre has a larger force, and the geogrid root and the geogrid tail play a similar function.

Fig.14 presents distributions of geogrid strains of model 2 and model 3 along the wall depth. The strain distributions of the two models are similar; geogrid centres have largest strains and play important roles in the whole reinforcement length. For geogrid roots, the strains of the top-layer and bottom-layer geogrids are largest. For geogrid centre and geogrid tails, the strains at $\mathrm{H} / 3$ below backfill surfaces are largest. They are important seismic design points. Geogrid strains of model 2 were less than strains of model 3, which shows that the reinforced effect of geogrid in saturated sand decreases. Drainage measures of geogrid reinforced soil retaining walls must be taken well in the construction.

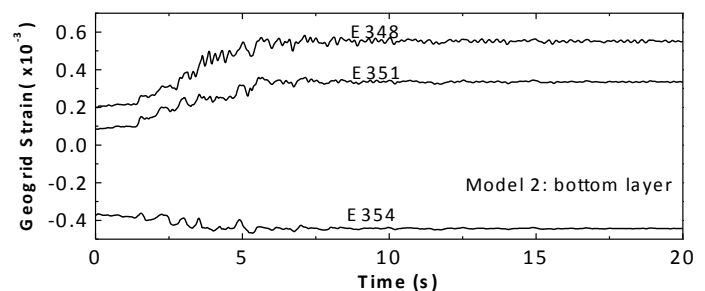

(a) bottom layer

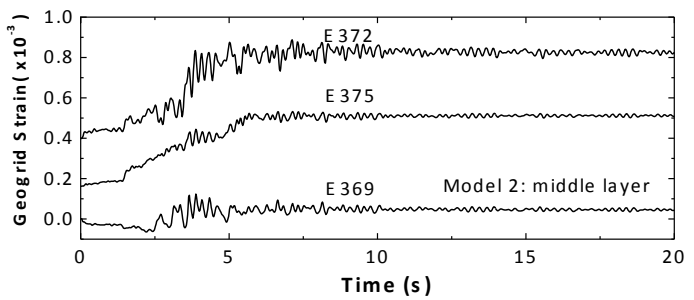

(b) middle layer

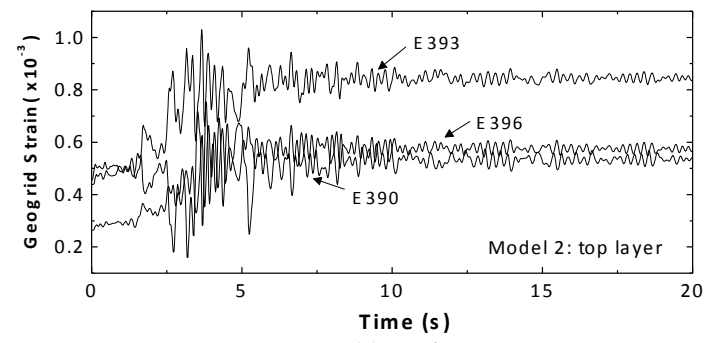

(c) top layer

Fig. 12. Time histories of geogrid strains of model 2

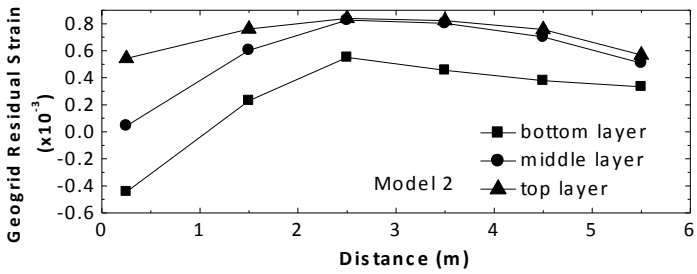

Fig. 13. Distributions of geogrid strains along geogrid lengths

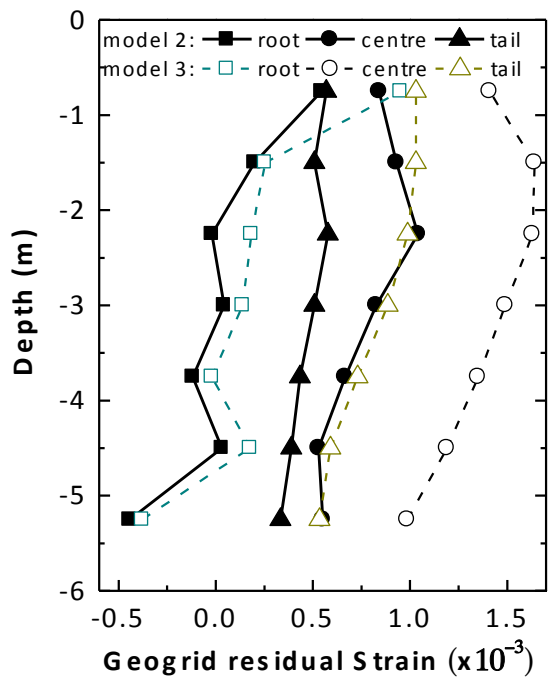

Fig. 14. Distributions of geogrid strains along the depth of the reinforced wall

\section{Conclusions}

By comparisons of seismic performances of retaining walls, some conclusions are as follows:

(1) The distinct decrease of lateral deformations of a geogrid reinforced soil retaining wall with saturated backfill sand indicates geogrids could still effectively decrease seismic lateral displacements of walls with liquefied backfill soil.

(2) The geogrid layers could effectively decrease seismic settlements of backfill surfaces close to retaining walls, but it is more important to construct good drainage measures.

(3) The geogrid layers could effectively decrease the development of excess pore pressures especially in the middle-layer geogrid reinforced soil. Geogrids provide a liquefaction mitigation function for the reinforced soil retaining wall with saturated sand.

(4) Strains of geogrid centres have largest strains and play important roles in the whole reinforcement length, and geogrid centres are key parts in seismic designs and engineering constructions.

(5) For geogrid roots, strains of top-layer geogrids are largest. For geogrid centres and geogrid tails, strains at $\mathrm{H} / 3$ below the backfill surface are largest. They are also important seismic design points.

(6) The decrease of the reinforced effect of geogrids in saturated sand shows it is important to construct good drainage measures of geogrid reinforced soil retaining walls in the constructions.

\section{Acknowledgments}

The authors appreciate the support of the National Natural Science Foundation of China (No. 51109099.). 


\section{References}

1. Huang, C.C.. "Investigations of soil retaining structures damaged during the Chi-Chi (Taiwan) earthquake", Journal of the Chinese Institute of Engineers,23(4), 2000, pp.417-428.

2. K.Z.Z. Lee, N.Y. Chang, H.Y. Ko. "Numerical simulation of geosynthetic-reinforced soil walls under seismic shaking", Geotextiles and Geomembranes; 28, 2000, pp.317-334.

3. J.Izawa and J. Kuwano. "Centrifuge shaking table tests on saturated reinforced soil walls", Proceedings of the 4th Asian Regional Conference on Geosynthetics, Shanghai, China, June 2008, pp. 17-20.

4. S. Rajesh, B.V.S. Viswanadham. "Hydromechanical behavior of geogrid reinforced soil barriers of landfill cover systems", Geotextiles and Geomembranes, 29(1),2001, pp.:51-64.

5. Luan Mao-tian, Li Jing-feng, Xiao Cheng-zhi etc. "Numerical Analysis of Performance of Geo-grid Reinforced Retaining Walls by nonlinear FEM", Chinese Journal of Rock Mechanic and Engineering; 24(14), 2005, pp.2428-2433.

6. Huabei Liu, Xiangyu Wang, Erxiang Song. "Reinforcement load and deformation mode of geosynthetic-reinforced soil walls subject to seismic loading during service life", Geotextiles and Geomembranes, 29, 2010, pp.:1-16.
7. Qiang Ma, Junjie Zheng, Jun Zhang. "Studying Tensile Forces of Geogrid Reinforcement in Reinforced Soil Bridge Approach", Disaster Advances, Vol.6 (S1), 2013, pp.356-362.

8. Gui Yang, Yanchen Liu, Chengpeng Zhang. "Experimental study on dynamic deformation characteristics of reinforced rockfill material", Disaster Advances, Vol.6 (13), 2013, pp.190-197.

9. Iai S, Matsunaga Y, Kameoka T, "Parameter identification for a cyclic mobility model”, Rep Port Harbour Res Inst, 29(4), 19990, pp.57-83.

10. O. Ozutsumi, S. Sawada, S. Iai, Y. Takeshimab, W. Sugiyamaa, T. Shimazu, "Effective stress analyses of liquefaction-induced deformation in river dikes", Soil Dynamics and Earthquake Engineering, 22, 2002, pp. 1075-1082.

11. Tetsuo Tobita, Susumu Iai, and Tomotaka Iwata. "Numerical Analysis of Near-Field Asymmetric Vertical Motion. Bulletin of the Seismological Society of Americax, 100(4), 2002, pp.14561469.

12. Mahmoud N. Hussien, Tetsuo Tobita, Susumu Iai and Kyle M.Rollins, "Soil-pile separation effect on the performance of a pile group under static and dynamic lateral loads", Canadian Geotechnical Journal, 47, 2010, pp.1234-1246. 